\title{
ENTREVISTA COM A PROFA. DRA. DIANA LUZ PESSOA DE BARROS: A ESTRATÉGIA ENUNCIATIVA NOS DISCURSOS DE ÓDIO QUE MARCAM AMBIENTES POLÍTICOS E SOCIAIS NA CONTEMPORANEIDADE
}

\author{
Fernando Moreira ${ }^{1}$ \\ Joyce Lopes ${ }^{2}$
}

RESUMO: Expoente da Semiótica de orientação francesa no Brasil, Diana Luz Pessoa de Barros analisa, nesta entrevista a Fernando Moreira e a Joyce Lopes, estratégias enunciativas da nova extrema direita que passaram a marcar os discursos políticos e sociais ao redor do mundo em demonstraçôes explícitas odiosas à alteridade.

PALAVRAS-CHAVE: Extrema direita. Bolsonarismo. Mounk. Diana Luz Pessoa de Barros. Bannon.

\section{THE ENUNCIATIVE STRATEGY IN HATE SPEECHES THAT MARK CONTEMPORARY POLITICAL AND SOCIAL ENVIRONMENTS}

ABSTRACT: An exponent of French-oriented Semiotics in Brazil, Diana Luz Pessoa de Barros analyzes, in this interview by Fernando Moreira and Joyce Lopes, enunciative strategies from the new far-right wing that have come to mark political and social discourses around the world in explicit odious statements to the otherness.

KEYWORDS: Far-right wing. Bolsonarism. Mounk. Diana Luz Pessoa de Barros. Bannon.

1 Universidade de São Paulo (Usp), Faculdade de Filosofia, Letras e Ciências Humanas, São Paulo - SP - Brasil. Bolsista CNPq. Mestrando em Semiótica e Linguística Geral. Orcid: http://orcid.org/0000-0001-8903-4415. fernando_moreira@usp.br.

2 Universidade de São Paulo (Usp), Faculdade de Filosofia, Letras e Ciências Humanas, São Paulo - SP - Brasil. Bolsista CAPES. Doutoranda em Semiótica e Linguística Geral. Orcid: https://orcid.org/0000-0002-1348-6551. joycednlopes@gmail.com. 
Uma linguagem retórica, intensa e intensificada, amplificada ainda mais em ambientes que, por sua natureza, já expandem a agudez afiada da língua, como o é a internet, produzindo discursos de desqualificação do outro. As palavras da entrevistada desse dossiê parecem um desenho fidedigno do que se observa nos discursos políticos e sociais contemporâneos a que temos acesso, diante de revisionismos históricos e de ataques a explicaçóes racionais, que buscam encontrar cientificidade como respostas à complexidade que nos rodeia. Nesse campo, entre outras estratégias de confusão informativa, encontram-se as fake news.

No escopo da proposta de indicar uma aproximação interdisciplinar possível e necessária entre os estudos da linguagem e as Ciências Sociais (GREIMAS, 1976), fazemos uso da relevante análise de uma das principais, se não a mais proeminente, pesquisadora brasileira do discurso na linha de estudos que provém da tradição francesa, também conhecida como Semiótica Discursiva, ou greimasiana. Diana Luz Pessoa de Barros ${ }^{3}$ é docente da Universidade de São Paulo e do Mackenzie, foi pupila, na França, dos autores mais festejados entre os estudantes do discurso, como o próprio Greimas e Roland Barthes. Seus estudos mais recentes tratam de discursos preconceituosos e intolerantes (BARROS, 2015a, 2015b). Pessoa de Barros nos mostra a riqueza analítica, também para um estudante das Ciências Sociais, de se conhecer estratégias linguísticas que caracterizam esses discursos, tornando pesquisas nesse campo interdisciplinar ainda mais coesas, visto que entre as bases de fundação da própria Semiótica estão as Ciências Sociais.

No que tangencia o campo político, o sujeito do discurso que faz uso de estratégias preconceituosas e intolerantes acaba encontrando, no cenário atual, identificação por parte de seu interlocutor, na medida em que seu éthos passa a ser o daquele que teve a coragem de "ir contra aquilo que não deveria ser tolerado socialmente". Barros mostra que o jogo discursivo direciona um saber e um poder e, por fim, um fazer, desde que haja um sistema de valores comum entre destinadores e destinatários de determinada mensagem. Nesse jogo, a aceitação e a inclusão sociais só têm espaço quando há a valoração positiva da mistura, da heterogeneidade, da alteridade sociais, o que não ocorre quando se trata de discursos que valorizam o discreto, uma pretensa pureza, seja de raça ou de valores, ou a triagem, na terminologia de Claude Zilberberg (2004), a quem coube inaugurar os estudos tensivos no campo semiótico. Ter ciência desses jogos de

\footnotetext{
3 Diana Luz Pessoa de Barros é uma das mais importantes, quiçá a principal, estudiosa da Semiótica Discursiva no Brasil. Docente Universidade de São Paulo e Mackenzie. Orcid: http://orcid.org/0000-0001-5182-6767. Lattes: http://lattes.cnpq.br/4742321400577426.
} 
coerções linguísticas é saber que a linguagem, como percebeu Barthes (1989 [1978]) em Aula, sempre será um projeto de poder.

1) Como estudiosa do discurso pela análise ferramental da chamada Semiótica discursiva, seus interesses recentes de pesquisa (BARROS, 2015a, 2015b) se voltam para os discursos preconceituosos e para os discursos intolerantes. Entende-se que possa haver um impacto no papel das trocas comunicacionais, influenciadas pelo perfil do suporte em que se produz um enunciado. A internet trouxe uma nova configuração de enunciação à sociedade pós-moderna, sendo apontada por muitos como a grande revolução do século XX (CASTELLS, 2000; LÉVY, 1993, 1999, 2001; QUÉAU, 1993). Em seu trabalho, como avalia o conteúdo dos discursos a partir de um suporte ou forma de expressão com potencial de produzir novos efeitos de sentido táo diferentes dos que reconhecíamos até então?

D.L.P.B. - Eu estava trabalhando em uma pesquisa, com bolsa CNPq, sobre intolerância discursiva, preconceito discursivo em geral, independentemente do tipo de discurso, do gênero discursivo. Ao trabalhar com isso, fui percebendo, cada vez mais, que boa parte dos textos que eu analisava era divulgada, criada, na internet. Com isso, resolvi pesquisar o papel que a internet tinha, como funcionava em relação à construção desses discursos intolerantes. Está mais do que claro que a internet não é a responsável pelo aparecimento dos discursos intolerantes, mas, devido às características do discurso na internet, de alguma forma, ela contribui para exacerbar essa intolerância, para produzir essas ondas de intolerância, de preconceito. Eu trabalhei, então, sobre a complexidade discursiva na internet (BARROS, 2015a). Nesse texto, a minha proposta é de que, em primeiro lugar, a internet se caracteriza, claramente, pela complexidade entre fala e escrita. A complexidade que estou usando é em sentido semiótico, quer dizer, a internet não é, ao mesmo tempo, fala e escrita, porque são dois contrários que não podem ser verdadeiros ao mesmo tempo, mas essa relação é do tipo que Zilberberg (2011 [2006]) vai chamar de concessiva, ou seja, o que caracteriza a internet é precisamente que: embora a fala ... também a escrita. $\mathrm{Ou}$, embora a escrita, também a fala. O complexo que pode se formar não é causal. $\mathrm{O}$ discurso na internet é marcado por essa complexidade concessiva, que funciona como um complexo desequilibrado, na maior parte das vezes, porque ora você diria: embora fala ... escrita; ora você diria, para a internet, embora escrita, fala. Isto é, ora você desequilibra em favor da fala, ora em favor da escrita. Um exemplo: no aplicativo WhatsApp há um desequilíbrio em favor da fala, ainda que o 
plano da expressão seja a escrita (em geral, pois há, também, as mensagens de voz). Desequilibra-se em favor da fala, visto que há todas as marcas da oralidade. Por outro lado, em mensagem por e-mail, desequilibra-se em favor da escrita. No jornal online há traços tanto de fala quanto de escrita. Tudo isso faz com que a internet seja formal e informal; passageira (como a fala) e duradoura (como a escrita), cria efeitos de sentido de aproximaçáo e de distanciamento. Esse conjunto leva a duas características básicas do discurso na internet, a saber, o excesso de tonicidade (próprio da fala, da interatividade) e, ao mesmo tempo, o excesso de extensão, visto que na internet nada se apaga, além do alcance enorme que ela tem (características da escrita). Há, ainda, na internet, a complexidade entre as instâncias pública e privada, em que usuários tornam escolhas e usos individuais, leis públicas. Ao mesmo molde da fala e da escrita, podemos observar outra mistura: embora público, privado; embora privado, público, simultaneamente.

2) O uso de dados na internet se transformou em plataforma de construção de contratos de veridicção, ou seja, define, em muitos casos, o nível de confiabilidade que um enunciatário (interlocutor) irá depositar em um texto ou em um discurso. Esse potencial tem sido medido matematicamente e os algoritmos ditam conteúdos, formas etc. Há denúncias de uso político, como na eleição americana, a partir de colaboração russa em favor de Donald Trump contra Hillary Clinton (INVESTIGAÇÃO..., 2019) e, aqui no Brasil, por meio da chamada patrulha virtual de Bolsonaro, sob os auspícios de empresas brasileiras que contrataram uma agência espanhola para fazer disparos automáticos de mensagens (MELLO, 2019), contrariando a determinação do Tribunal Superior Eleitoral (TSE) de que apenas fontes oficiais de campanha podem contratar serviços de divulgação de candidatos e de que as ferramentas de automatizaçáo responsáveis por disparo em massa são proibidas, além de poder ser uma maneira de ocultar a contabilização de gastos de campanha acurada. Como a Semiótica pode contribuir para se pensar o mundo do discurso, a partir desses novos arranjos manipulativos?

D.L.P.B. - Embora a internet não seja a responsável por criar o preconceito e a intolerância, exacerba esses elementos no discurso e, por essa característica, é lógico que está sendo um instrumento político fundamental. Em Cadernos de Estudos Linguisticos, da Unicamp (BARROS, 2016), eu trabalhei com o ator da enunciação excessivo, tomando outros exemplos, como o caso do sujeito conhecido como rei do camarote, inclusive fora da internet, justamente para mostrar características desse enunciador que usa um discurso hiperbólico, que se utiliza 
de palavróes. É um tipo de discurso que, em geral, não se tornava um discurso público a não ser naqueles veículos muito sensacionalistas. Com a internet, quebrou-se essa separação entre público e privado. Todos esses discursos se tornaram públicos. Então, isso também se fez no jogo político. No estudo mencionado, analisei discursos de sujeitos que faziam apologia ao estupro, à homofobia, à misoginia, ao machismo, ao preconceito contra intelectuais de esquerda e de Humanidades em detrimento dos de outras áreas do conhecimento, como a Engenharia, cujo estereótipo é o da masculinidade heteronormativa. Há, nesses casos, traços do discurso intolerante, que acentuam ideias, intensificam-nas, por meio de estratégias linguístico-discursivas, retóricas, uso de muitas figuras, principalmente hipérboles, metáforas, metonímias, uso de generalizaçôes como ataques do tipo: toda mulher não presta. O que nós temos visto no mundo político, principalmente, com as fake news, é isso: o uso de uma linguagem retoricamente intensa, intensificada, em um lugar, como a internet, que enrijece ainda mais esse discurso. As fake news, além de serem um discurso da mentira, são um discurso de desqualificação do outro, portanto, têm todas as características dos discursos preconceituosos e intolerantes.

3) O ultradireitista Steve Bannon, que foi estrategista de campanha de Donald Trump, em entrevista à repórter Patrícia Campos Mello do jornal Folha de São Paulo (MELLO, 2018), teceu dezenas de elogios ao presidente brasileiro e a seu filho, Eduardo. Chegou a comparar Bolsonaro, o pai, aos representantes da extrema direita Viktor Orban (primeiro-ministro da Hungria), a Trump, a Nigel Farage (líder pró-Brexit no Reino Unido). Disse, ainda, que "o populismo de centro-direita, conservador e nacionalista, é uma das tendências mais importantes do século XXI".

Isso nos faz lembrar a recomendação de Sérgio Buarque de Holanda (2014 [1936], p. 36) de que em face de uma "falta de coesão em nossa vida social [...] erram profundamente aqueles que imaginam na volta à tradição, a certa tradição, a única defesa possível contra nossa desordem". Didaticamente, é possível fazer uma ligeira análise semiótica desse jogo de manipulaçóes discursivas?

D.L.P.B - Acredito que Bannon estivesse tentando justificar as estratégias de fake news dizendo que são para colocar em prática um tipo de situação política que ele considera boa. Isso, não há dúvida, foi feito de uma maneira sagaz e inteligente. Ele está justificando uma prática muito nociva que nós tivemos, que os Estados Unidos tiveram. Já a citação de Holanda, a meu ver, referia-se a outros tipos de valores tradicionais. Pode até ser pensada, de alguma maneira, 
no contexto atual, contudo, essa atmosfera atual é tão extremada que, na minha avaliação, seria algo que Holanda nem poderia prever que ocorresse nos dias de hoje.

4) Em O povo contra a democracia: por que nossa liberdade corre perigo e como salvá-la, Yascha Mounk (2019) observa que democracia e liberalismo; pilares de um sistema que parecia inquestionável e levaram Francis Fukuyama (1992) a teorizar o Fim da História, imaginando que avanços eram universais, irreversíveis e levariam o mundo a uma convergência econômica, social etc.; passaram por revisionismos. A característica dos populistas de direita que emergiram em todo o mundo, especialmente neste começo de século XXI, é de um grande iliberalismo, mas democrático, ao que Mounk (2019, p. 30) chamou de "democracia sem direitos". O pensamento se baseia na ideia de que direitos individuais e vontade popular nem sempre andam juntos, com base na observação de que há uma quebra de confiança na figura do político tradicional e de que os populistas são vistos pelo povo como líderes honestos "que partilhem da opinião pura das pessoas e esteja disposto a lutar em nome delas" e que "depois que esse líder honesto estiver no comando, precisa acabar com os obstáculos institucionais que o impeçam de cumprir a vontade do povo" (MOUNK, 2019, p. 23). Nesse contexto, os partidários sabem deliberadamente que "seu líder mente, dissemina mensagens de ódio e não passa de um bronco. Convencidos de que os políticos tradicionais nada têm a lhes oferecer, é precisamente isso que os atrai nele" (MOUNK, 2019, p. 12). Muitos países que optaram pela radicalização à direita mudaram Constituiçóes, concedendo a líderes populistas poderes expandidos, restringindo liberdades políticas e civis da população e "embora na campanha não raro prometam erradicar a corrupção, os países que governam ficaram, em média, mais corruptos" (MOUNK, 2019, p. 11, grifo do autor). Como podemos avaliar essa complexidade de sentidos sob o ponto de vista de valores, do fazer manipulador do enunciador (aquele que diz em um discurso) e do fazer interpretativo do enunciatário (aquele a quem se dirige o discurso)? Seria prudente se pensar em uma semiótica passional da ação maquiavélica, a partir do termo semiótica maquiavélica, de Aldama (2019)?

D.LP.B. - Há estratégias comuns nos discursos políticos, como as de aproximação e as de distanciamento, o que também tem a ver com o público que se pretende atingir. Já houve pesquisas comparadas sobre perfil do eleitorado, em que se percebeu que para o eleitorado de origem latina funciona melhor a estratégia de aproximação. Por outro lado, a de distanciamento, no contexto histórico 
dessas pesquisas, foi mais adequada ao eleitorado anglo-saxão. Esse é um ponto que se refere, por exemplo, ao uso da terceira pessoa nos discursos direcionados a este público e, em primeira, para aquele. Estratégias de aproximação ou distanciamento acontecem com frequência. Uma questão diferente é a estratégia para criar identificação de valores no outro, o que é uma questão de interpretação, de veridicção, o que tenho usado em minha pesquisa em curso sobre os discursos mentirosos. Na Semiótica, há o destinador que propóe um contrato veridictório ao seu destinatário. Nessa proposição, apresenta-se algo que parece verdadeiro e se pretende que o destinatário interprete dessa maneira. Ou, de modo oposto, há a tentativa de mostrar que algo que parecia falso é verdadeiro. É uma espécie de jogo discursivo de convencimento. Interpretar é passar do parecer, ou do não parecer, ao ser, ou ao não ser. O destinatário interpreta de acordo com conhecimentos que tem, em crenças que tem, em emoçóes, sentimentos e na capacidade de persuasão do destinador. O que se nota, atualmente, é que essa interpretação tem ocorrido, principalmente, com base nas crenças e emoçóes e não com base nos saberes, somente no crer e no sentir. Quando se identifica o sentimento e a emoção do outro - e isso as máquinas também fazem hoje ao estabelecerem perfis com base em atividades dos usuários em ambientes virtuais, como nos sites e em aplicativos, além de coleta de dados de buscas por palavras-chave na internet - estabelece-se, com clareza, ao destinador-manipulador, qual o discurso ele deve usar para que o destinatário interprete como verdadeira a sua mensagem. É por isso que as fake news, por mais absurdas, são usadas de duas formas: parte das pessoas sabe que se trata de informaçóes falsas, mas as dissemina para convencer outras pessoas, justamente porque essas outras acreditam que sejam verdadeiras. Isso ocorre simplesmente porque aquilo que se diz está de acordo com sentimentos e emoçóes do destinatário. Outra estratégia usada pelo destinador, que também acontece nesse tipo de política, é utilizar informaçóes nas quais se sabe que o destinatário acredita, o que cria uma relação sensorial, emocional, sentimental entre ambos. A partir disso, introduzem-se outros elementos, nos quais esse interlocutor, provavelmente, não acreditava antes e vai passando a acreditar até que se possa dizer qualquer absurdo e haverá quem acredite.

5) Começamos com o mais atual, mas é necessário tentarmos avaliar um pouco da gênese de discursos políticos e sociais que circulam, atualmente, não apenas no Brasil. Há várias versóes que justificam o retorno ao protagonismo de discursos conservadores. Algumas delas se apoiam em explicaçóes econômicas, outras em raízes psicossociais. Sob o olhar semiótico, como podemos pensar nesse ressurgimento de defesas apaixonadas e incautas da pena de morte, do ódio 
a grupos socialmente sufocados e silenciados por séculos, como negros, mulheres e homossexuais, em um contexto em que a tais grupos se começava a oferecer o que lhes era de direito: lugares possíveis de existência cidadã? Em sua avaliação, podemos chamar tais discursos de intolerantes? Para a discussão, apresentamos algumas reflexôes do filósofo André Comte-Sponville (2000 [1995], p. 177) que afirma: "uma tolerância infinita seria o fim da tolerância". Não deixamos, contudo, de considerar níveis de gradaçóes nessa afirmação propostas pelo próprio autor, ao problematizar que uma sociedade democrática que banisse "todos os partidos não democráticos seria muito pouco democrática, assim como uma democracia que os deixasse fazer tudo [...] seria democrática demais, ou antes, mal democrática demais" (COMTE-SPONVILLE, 2000 [1995], p. 177).

D.L.P.B. - Penso que temos de opor discursos intolerantes não aos tolerantes, embora chegar à tolerância muitas vezes já represente um ganho, mas é preciso opor os discursos intolerantes aos de aceitação e inclusão social. $\mathrm{O}$ discurso da direita não é obrigatoriamente intolerante, preconceituoso, contudo, o discurso da extrema direita, hoje no Brasil, é o que eu chamo de discurso intolerante: considera que certas pessoas não cumpriram certos contratos sociais, como heterossexualidade, religião etc., portanto, devem ser temidos, odiados e punidos. Os discursos intolerantes são os do ódio e os do medo e são sempre passionais: ódio a quem se considera que não cumpriu os contratos sociais e medo do diferente. Na nossa sociedade, o medo e o ódio não são paixốes valorizadas ou moralizadas positivamente. Em geral, são moralizadas negativamente, já o amor e a coragem são valorizados positivamente em nossa sociedade. Dessa maneira, uma pergunta que eu me fazia é a respeito do porquê de haver discursos políticos que usam a intolerância como plataforma. Quem trabalha em outros campos, com o da tolerância e não o da linguagem, mas serve para a gente, percebeu que discursos intolerantes ocorrem quando seus destinadores acreditam existir algo que não possa ser tolerado, que deva ser combatido. Seriam, segundo essa lógica, intolerantes ao que não pode ser tolerado. Sob essa visão, homossexuais não deveriam ser tolerados por prejudicarem a "boa família brasileira", não se poderia tolerar o negro porque isso impediria um pretenso branqueamento da nossa sociedade. O político que faz uso de discursos dessa natureza como estratégia passa a ser visto como aquele que teve a coragem, não permanecendo na instância do medo, de ir contra o que não deveria ser tolerado socialmente e é isso que tem ocorrido. Zilberberg (2004) fala, em seu texto sobre a mestiçagem, em melhoração e pejoração. Só há aceitação quando se considera que o diferente faz melhorar a sociedade, quando isso passa fazer parte de um sistema de valores 
para os indivíduos. Ter uma sociedade em que se misturam heterossexuais e homossexuais, negros, brancos, amarelos, cor-de-rosa, não importa, é um ganho. A diversidade passa a ser um ganho. Só nessa hora se tem a aceitação.

6) Prospectivamente, poderíamos aventar a possibilidade de um maior equilíbrio entre enunciadores, a depender de resultados desses embates enunciativos contemporâneos, ou, em sua avaliação há apenas expectativa de retrocessos?

D.L.P.B. - Eu espero que a gente volte a ser uma sociedade melhor, mas eu penso que as perdas estáo sendo muito grandes e que, a nós, vai nos custar muito.

\section{REFERÊNCIAS}

ALONSO ALDAMA, J. As transparências enganam. Estudos Semióticos, São Paulo, v.15, n.1, p. 152-161, 2019. Dossiê temático "Discursos políticos na contemporaneidade: desafios teóricos e analíticos". Editores convidados: Oriana N. Fulaneti e Alexandre Marcelo Bueno. Disponível em: https:/www.revistas.usp.br/ esse/article/view/160195. Acesso em: 5 nov. 2019.

BARROS, D. L. P. de. Estudos discursivos da intolerância: o ator da enunciação excessivo. Cadernos de Estudos Linguísticos, Campinas, v. 58, p. 7-24, 2016.

BARROS, D. L. P. de. A complexidade discursiva na internet. CASA: Cadernos de Semiótica Aplicada, Araraquara, v.13, n.2, p. 13-31, 2015a. Disponível em: https:// periodicos.fclar.unesp.br/casa/article/view/8028. Acesso em: 3 jul. 2020.

BARROS, D. L. P. de. Dominação, trapaça e conhecimento pela linguagem. Revista da ABRALIN, Curitiba, v.14, n.2, p. 53-71, 2015b. Disponível em: https://revistas. ufpr.br/abralin/article/view/42549. Acesso em: 3 jul. 2020.

BARTHES, R. Aula. Trad. Leyla Perrone-Moisés. São Paulo: Cultrix, 1989 [1978].

CASTELLS, M. A Sociedade em rede: A era da informação: economia, sociedade e cultura. São Paulo: Paz e Terra, 2000. v.1.

COMTE-SPONVILLE, A. Pequeno Tratado das Grandes Virtudes. Trad. Eduardo Brandão. São Paulo: Martins Fontes, 2000 [1995].

FUKUYAMA, F. O fim da História e o último homem. Rio de Janeiro: Rocco, 1992.

GREIMAS, A. J. Semiótica e Ciências Sociais. Trad. Álvaro Lorencini e Sandra Nitrini. São Paulo: Cultrix, 1976. 
HOLANDA, S. B. de. Raízes do Brasil. 27. ed. São Paulo: Companhia das Letras, 2014 [1936].

INVESTIGAÇÃO de republicanos revela que Rússia ajudou Trump em 2016. Estado de Minas, Belo Horizonte, 08 out. 2019. Internacional. Disponível em: https://www. em.com.br/app/noticia/internacional/2019/10/08/interna_internacional,1091243/ investigacao-de-republicanos-revela-que-russia-ajudou-trump-em-2016.shtml. Acesso em: 02 nov. 2019.

LÉVY, P. A conexão planetária: o mercado, o ciberespaço, a consciência. São Paulo: Ed. 34, 2001.

LÉVY, P. Cibercultura. São Paulo: Ed.34, 1999.

LÉVY, P. As tecnologias da Inteligência: o futuro do pensamento na era da informática. Rio de Janeiro: Ed. 34, 1993.

MELLO, P. C. Empresas contratam disparos pró-Bolsonaro no WhatsApp, diz espanhol. Folha de Sáo Paulo, São Paulo, 18 jun. 2019. Poder. Disponível em: https://www1.folha.uol.com.br/poder/2019/06/empresas-contrataram-disparos-probolsonaro-no-whatsapp-diz-espanhol.shtml. Acesso em: 02 nov. 2019.

MELLO, P. C. Capitalismo esclarecido e populismo de Bolsonaro aproximarão o Brasil dos EUA, diz Steve Bannon. Folha de Sáo Paulo, São Paulo, 29 out. 2018. Poder. Disponível em: https://wwwl.folha.uol.com.br/poder/2018/10/capitalismoesclarecido-e-populismo-de-bolsonaro-aproximarao-o-brasil-dos-eua-diz-stevebannon.shtml. Acesso em: 02 nov. 2019.

MOUNK, Y. O povo contra a democracia: por que nossa liberdade corre perigo e como salvá-la. Trad. Cássio de Arantes Leite e Débora Landsberg. Sáo Paulo: Companhia das Letras, 2019.

QUÉAU, P. O tempo do virtual em Imagem Máquina: a era das tecnologias do virtual. Org. André Parente. São Paulo: Ed.34, 1993.

ZILBERBERG, C. Elementos de Semiótica Tensiva. Trad. Ivã Carlos Lopes, Luiz Tatit e Waldir Beividas. São Paulo: Ateliê Editorial, 2011 [2006].

ZILBERBERG, C. As condições semióticas da mestiçagem. Trad. Luiz Tatit e Ivã Carlos Lopes. In: CAÑIZAL, E. P.; CAETANO, K. E. (org.). O olhar à deriva: mídia, significação e cultura. São Paulo: Annablume, 2004. p. 69-101. 